\title{
Family-centred care in intensive care units
}

Family-centred care (FCC) is a partnership approach to health decisionmaking between the family and the healthcare provider. FCC has been recognised by numerous medical societies, healthcare systems, legislative bodies and the Institute of Medicine as integral to patient health, satisfaction and healthcare quality. ${ }^{[1-3]}$

FCC was codified in 1992 by the Institute for Patient and FamilyCentered Care in the USA, which described elements of FCC as recognising the family as a constant in the patient's life and facilitating family-professional interactions at all levels of healthcare. It requires that the patient's family participates and collaborates with healthcare professionals as partners in care. The concept emphasises that a patient's healthcare decisions should be contextualised in terms of their broader life experiences. FCC is commonly used to describe optimal health as an experience of families. The term is frequently accompanied by terms such as 'partnership' and 'collaboration', and families as 'experts' to describe the process of care delivery. ${ }^{[1,4,5]}$

The provision of FCC in the intensive care unit (ICU), inclusive of neonatal, paediatric and adult units, is equally important as in the rest of the hospital's establishment and has to be considered in the care of critically ill patients. ICU healthcare professionals should therefore incorporate family members into the provision of critical care. Critical illness of loved ones has enormous effects on their family members, with approximately one-quarter to half of family members of critically ill patients experiencing significant psychological symptoms, including acute stress, post-traumatic stress, generalised anxiety and depression, both during and after the critical illness of their loved one. ${ }^{[6-8]}$ The combined impact on family members may result in what has been termed 'post-intensive care syndrome-family' (PICS-F) ${ }^{[9]}$

Furthermore, family members are often placed in the position of acting as surrogate decision-makers for critically ill patients, and support for and effective communication with family members will facilitate highquality and ethical shared decision-making in the ICU. ${ }^{[9]}$ In the neonatal intensive care unit (NICU), FCC shifts the attention from the disease alone to the patient in the context of their family and community. Family members, especially parents, are natural advocates for the neonatal patient for whom the emotional, social and developmental needs are serious and urgent. ${ }^{[10]}$

In addition, being involved in surrogate decision-making is associated with higher levels of distress among family members, and matching family preference with their role in decision-making may reduce this stress. Patients often want family members involved in decision-making about their care, and most patients with chronic illness report that their family members' perspectives are important in their care decisions. Involvement of patients' families is especially important in the ICU because patients are too ill to advocate for themselves. ${ }^{\left[{ }^{9]}\right.}$ For all these reasons, high-quality FCC should be considered as a basic skill for ICU healthcare professionals.

For patient-centred or family-centred care models to be operationalised in the ICU, patients' family members and surrogate decision-makers must become active partners in decision-making and care. ${ }^{[11]}$

Despite the importance of FCC and the involvement of family in the delivery of care, the implementation thereof has not been smooth because of tensions in communication that seem to be an inevitable occurrence in interactions between families and health professionals.
Limited understanding of the principles guiding FCC, as well as language and cultural challenges related to FCC, might influence its full implementation. ${ }^{[8,13]}$ Within the paediatric ICU (PICU) environment, it has been suggested that FCC principles are more than simply 'familyinvolvement in decision-making, but should also incorporate how parents experience systems, the healthcare environment and facility design. ${ }^{[12]}$

The current edition of the SAJCC contains two articles that address some of the tensions related to the delivery of FCC in the contexts of emergency and paediatric critical care in South Africa (SA). The first article in this issue ${ }^{[14]}$ emphasises that, in order for family members to adapt to a healthcare establishment (e.g. an emergency department), it is important that healthcare professionals adhere to relational and participatory family-centered practice behaviours. Relational behaviour is essential to build effective and authentic relationships with families, while participatory behaviours are action-orientated and aimed at assisting families in capacity building. The authors state that it is important to note what families actually need as opposed to what healthcare professionals assume they need. Healthcare professionals should therefore identify the preferences of each family, as this increases trust and indicates respect for the families. The importance of providing support to aid families and include them in the decision-making process was echoed by this study. Furthermore, healthcare professionals should engage in reflection on their own interactions with families in order to maximise patient -and family-centered care. It was also suggested that staff should be offered formal education regarding the needs of families, particularly in view of SA's diverse cultural context. ${ }^{[14]}$

Findings from a previous study conducted amongst emergency departments in the Durban area ${ }^{[15]}$ recommended that a family needs assessment should be included as part of every patient's assessment. In addition, evaluation of hospital policies and procedures for congruency with FCC, especially in relation to family-witnessed resuscitation and invasive procedures, is needed to promote family participation in patient care. Bereavement programmes to support staff in dealing with bereavement issues would be beneficial. Further research is warranted to improve FCC in the SA critical and emergency care context. ${ }^{[15]}$

It is acknowledged by the authors of the second article in this edition $^{[16]}$ that paediatric illness remains a major and stressful event for thir children and their family. Knowledge of parental needs and their perceptions of care are therefore necessary to improve the quality of PICU care. ${ }^{[16]}$ The study findings highlight that parents appreciate being informed about their child's condition, treatment and procedures, and being given explanations on the care. Parent participation in the decision-making process is thus essential. Davidson ${ }^{[11]}$ concurs in stating that for a FCC model to be operationalised in the ICU, patients' family members and surrogate decision-makers must become active partners in decision-making and care. Furthermore, the study highlights that elements of language and communication barriers, cultural competence, architectural and facility design, and parent participation must be considered as future research areas. ${ }^{[16]}$

Guidelines for FCC in neonatal, paediatric, and adult ICUs have been developed, which provide a summary of best practices as identified by the existing evidence to shape internal hospital policies related to supporting families in the ICU. Communication, clinician and family 
training, family presence, involvement and engagement, provision of consultative resources and environmental and organisational processes are all elements to consider when building an optimal programme of family-centred care in the ICU. ${ }^{[17]}$

\section{Portia Jordan \\ School of Clinical Care Sciences, Nelson Mandela University, Port Elizabeth, South Africa \\ portia.jordan@mandela.ac.za}

S Afr J Crit Care 2018;34(2):34-35. DOI:10.7196/SAJCC.2018.v34i2.369

1. Kuo DZ, Houtrou AJ, Arrango P, Kuhthauk A, Simmons JM, Neff JM. Family-centered care: Current application and future directions in paediatric health care. Matern Child Health 2012;16(2):297-305. https://doi.org/10.1007/s10 995-011-0751-7

2. Institute of Medicine, Committee on Quality of Health Care in America. Crossing the Quality Chasm: A New Health System for the 21st Century. Washington, DC: National Academy Press; 2001.

3. Stange KC, Nutting PA, Miller WL, et al. Defining and measuring the patient-centered medical home. J Gen Intern Med 2010;25(6):601-612. https://doi.org/10.1007/s11606-010-1291-3

4. Shields L. What is family-centered care? European J Person-centered Health Care 2015;3(2):139-144.

5. Clay AM, Parsh B. Patient- and family-centered care: It is not just pediatrics anymore. AMA J Ethics 2016;18(1):40-44. https://doi.org/10.1001/journalofethics.2016.18.1.medu3-1601
6. Davidson JE, Jones C, Bienvenu OJ. Family response to critical illness: Post intensive care syndromefamily. Crit Care Med 2012;40(2):618-624. https://doi.org/10.1097/CCM.0b013e318236ebf9

. Adelman RD, Tmanova LL, Delgado D, Dion S, Lachs MS. Caregiver burden: A clinical review. JAMA 2014;311(10):1052-1060.

8. Kon AA, Davidson JE, Morrison W, et al. Shared decision-making in ICUs: An American College of Critical Care Medicine and American Thoracic Society Policy Statement. Crit Care Med 2016;44(1):188-201. https://doi.org/10.1097/CCM.0000000000001396

9. Gerritsen RT, Hartog CS, Curtis JR. New developments in the provision of family-centered care in the intensive care unit. Intensive Care Med 2017;43(4):550-553. https://doi.org/10.1007/s134-017-4684-5

10. Judith S, Gooding, BA, Liza G, et al. Family support and family-centered care in the neonata intensive care unit: Origins, advances. Seminol Perinatol 2011;35(1):20-28. https://doi. org/10.1053/j.semperi.2010.10.004

11. Davidson JE. Family-centered care: Meeting the needs of patients' families and helping families adapt to critical illness. Crit Care Nurse 2009;29(3):28-34. https://doi.org/10.4037/ccn2009611

12. Macdonald ME, Liben S, Carnevale FA, Cohen SR. An office or a bedroom? Challenges for familycentred care in paediatric intensive care units. J Child Health Care 2012;16(3):237-249. https://doi. org/10.1097/01.pcc.0000448855.48155.ff

13. Shields L, Çavuşoğlu H, Pars H, Mamun AA. Measuring family-centred care: Working with children and their parents in a Turkish hospital. European J Person Centred Healthcare 2015;3(3):327-333. https://doi.org/10.5750/ejpch.v3i3.985

14. Emmamally W, Brysiewicz P. Family-centred practices of health care professionals in three province of KwaZulu-Natal, South Africa. S Afr J Crit Care 2018;34(2): 38-43. https://doi.org/10.7196/SAJCC.201.v34i2.358

15. Almaze JPB, de Beer J. Patient- and family-centred care practices of emergency nurses in emergency departments in the Durban area, KwaZulu-Natal, South Africa. S Afr J Crit Care 2018;33(2):59-65. https://doi.org/10.7196/SAJCC.2017.v33i2.317

16. Mol C, Argent A, Morrow B. Quality of family-centred care in a South African paediatric intensive care unit. S Afr J Crit Care 2018;34(2): 50-56. DOI:10.7196/SAJCC.201.v34i2.366

17. Davidson JE, Aslakson RA, Long AC, et al. Guidelines for family-centered care in the neonatal, pediatric, and adult ICU. Crit Care Med 2017;45(1):103-128. https://doi.org/10.1097/ CCM.0000000000002169

\section{There's more to weaning than just the lungs!}

Although life-sustaining, mechanical ventilation is associated with complications that can impact on mortality and morbidity. Therefore, weaning is initiated early during the course of mechanical ventilation, with the aim of liberation as soon as possible. In some cases, patients can be weaned quickly from mechanical ventilation, while others may take significantly longer, regardless of whether there are protocols or not. ${ }^{[1]}$

Extubation failure is associated with longer periods of mechanical ventilation, longer hospital stays and increased mortality. ${ }^{[1]}$ There are numerous measures and indices that have been developed to determine weaning and extubation suitability; however, the accuracy of these indices is yet to be convincingly and consistently shown. ${ }^{[2]}$ Of note, muscle strength and endurance have not been assessed as factors in any of the identified studies for weaning/extubation success, but both impact on weaning. One of the reasons for the lack of accuracy of weaning indices may be that the majority of these indices are derived from ventilatory parameters. Cardiovascular dysfunction prior to or during weaning is being increasingly recognised as a contributor to weaning failure ${ }^{[3]}$ Consciousness and psychological factors such as delirium, depression and anxiety have also been shown to affect weaning outcome. ${ }^{[4]}$ Nutrition and the underlying physiological status of the patient are also factors to consider. ${ }^{[2]}$ Furthermore, muscle weakness of both respiratory and peripheral muscles has also been associated with weaning failure. ${ }^{[5-9]}$ Many of the aforementioned factors may be ameliorated through rehabilitative interventions during the course of mechanical ventilation. ${ }^{[10]}$

In this issue of SAJCC, de Beer et al. ${ }^{[1]}$ aimed to determine, in a pilot study, whether measures of upper-limb and neck-muscle strength, as well as muscle endurance, are associated with spontaneous breathing trial (SBT) and/or extubation failure. The assessment of these potential contributors could provide a more holistic assessment of readiness to wean/extubate. Furthermore, assessment of these factors could help to develop patient-tailored rehabilitation interventions to assist with earlier liberation from mechanical ventilation. Upper-limb and neck muscles (upper trapezius, neck flexors and middle deltoid) were assessed using the Oxford scale, owing to their common innervation pathways with the respiratory muscles. The authors found that deltoid and neck flexor strength was associated with extubation failure, but not SBT failure. Additionally, a longer active cycling distance and time were associated with successful SBT or extubation.

While the concepts examined certainly warrant investigation, and a more holistic assessment of weaning readiness is needed, the results do, however, require caution and further validation. Admittedly, this is a pilot study with a relatively small population, with only two participants failing extubation (and likely owing to medical reasons). Additionally, the groups differed in age, length of stay in the intensive care unit (ICU) and duration of mechanical ventilation, all of which may impact negatively on weaning/extubation outcome. It is essential that other factors impacting on weaning/extubation outcomes, such as comorbidities and disease severity, are accounted for in the analysis, to fully understand the value of assessing upper-limb and neck-muscle strength and endurance to determine extubation readiness.

One has to question whether muscle endurance was adequately assessed in this study. ${ }^{[11]}$ Muscle endurance, by definition, is the ability of a muscle to sustain a submaximal load for a period of time, according to the American College of Sports Medicine guidelines. [12] The submaximal load should be individualised to the patient in a standardised manner (e.g. a percentage of their one-repetition maximum). In the present study, the same load was applied to all participants, regardless of their underlying strength. This raises the question as to whether endurance was adequately assessed in stronger patients, and assessed at all in the very weak patients.

Inspiratory muscle training (IMT) has the potential to improve weaning outcome in certain groups of patients; however, often it can only be initiated once patients can tolerate time off the mechanical 
ventilator. ${ }^{[13]}$ The concept of interneuron activation is interesting, and may provide the opportunity to indirectly train respiratory muscles in ventilated patients. Given that muscle weakness of both peripheral and respiratory muscles, often coexisting, is common in critically ill patients, confirmation of such interneuron activation in critically ill patients is required. ${ }^{[5]}$ There are various means to test muscle strength in critically ill patients, each with varying degrees of reliability. The Medical Research Council Sum Score (MRC-SS) assesses six muscle groups of the upper and lower limbs. It is frequently used in critically ill patients, and can identify ICU-acquired weakness. ${ }^{[1,15]}$ Furthermore, it has very good inter-rater reliability (intraclass correlation coefficients (ICC), 0.86 - 0.99), handgrip strength was also very good (ICC 0.89 - 0.97) and dynamometry was fair (ICC 0.62 - 0.96). ${ }^{[16]}$ Therefore, using a more comprehensive assessment of muscle strength (including respiratory muscles) could aid in more holistic intervention to facilitate liberation from the mechanical ventilator, and improved functional outcomes. The reliability of the Oxford scale in the ICU is yet to be determined, particularly regarding muscles such as the neck flexors and upper trapezius, and therefore requires further validation before being recommended as an assessment of weaning/extubation readiness.

Given the impact of weaning/extubation failure on mortality and morbidity, as well as the contribution of the musculoskeletal system to the success or failure of being liberated from mechanical ventilation, physiotherapists and rehabilitation specialists are integral to the weaning process. Many studies have investigated interventions such as IMT and peripheral muscle strengthening, using techniques such as neuromuscular electrical stimulation and early rehabilitation, to improve muscle strength and outcomes; however, these interventions have varying efficacy. ${ }^{[13,17-19]}$ Many questions remain as to how to identify at-risk patients early during the course of mechanical ventilation. What type of intervention should be initiated, when should it be initiated and at what dosage and frequency should it be performed? Furthermore, an understanding of the time course and underlying pathophysiology of muscle dysfunction is critical in developing assessment strategies and interventions in critically ill patients. In order to comprehensively answer these questions, we need rigorous studies of excellent methodological quality, and clearly defined outcome measures.

\section{A Lupton-Smith}

Division of Physiotherapy, Stellenbosch University, South Africa aluptonsmith@gmail.com

\section{S Afr J Crit Care 2018;34(2):2. DOI:10.7196/SAJCC.201.v34i2.371}

1. Beduneau G, Pham T, Schortgen F, et al. Epidemiology of weaning outcome according to a new definition. The WIND study. Am J Respir Crit Care Med 2017;195(6):772-783. https://doi. org $/ 10.1164 / \mathrm{rccm} .201602-0320 \mathrm{OC}$

2. Rafael Baptistella A, Sarmento FJ, Ribeiro Da Silva K, et al. Predictive factors of weaning from mechanical ventilation and extubation outcome: A systematic review. J Crit Care 2018;48:56-62 https://doi.org/10.1016/j.jcrc.2018.08.023

3. Pinsky MR. Breathing as exercise: The cardiovascular response to weaning from mechanical ventilation. Intensive Care Med 2000;26(9):1164-1166. https://doi.org/10.1007/s001340000619

4. Jubran A, Lawm G, Kelly J, et al. Depressive disorders during weaning from prolonged mechanical ventilation. Intensive Care Med 2010;36(5):828-835. https://doi.org/10.1007/s00134-010-1842-4

5. Dres M, Dube BP, Mayaux J, et al. Coexistence and impact of limb muscle and diaphragm weaknes at time of liberation from mechanical ventilation in medical intensive care unit patients. Am J Respir Crit Care Med 2017;195(1):57-66. https://doi.org/10.1164/rccm.201602-0367OC

6. De Jonghe B, Bastuji-Garin S, Sharshar T, Outin H, Brochard L. Does ICU-acquired paresis lengthen weaning from mechanical ventilation? Intensive Care Med 2004;30(6):1117-1121. https:// doi.org/10.1007/s00134-004-2174-z

7. Hermans G, De Jonghe B, Bruyninckx F, Van den Berghe G. Clinical review: Critical illness polyneuropathy and myopathy. Crit Care 2008;12(6):238. https://doi.org/10.1186/cc7100

8. Supinski GS, Morris PE, Dhar S, Callahan LA. Diaphragm dysfunction in critical illness. Chest 2018;153(4):1040-1051. https://doi.org/10.1016/J.CHEST.2017.08.1157

9. Goligher EC, Fan E, Herridge MS, et al. Evolution of diaphragm thickness during mechanical ventilation. Impact of inspiratory effort. Am J Respir Crit Care Med 2015;192(9):1080-1088 https://doi.org/10.1164/rccm.201503-0620OC

10. Schweickert WD, Pohlman MC, Pohlman AS, et al. Early physical and occupational therapy in mechanically ventilated, critically ill patients: a randomised controlled trial. Lancet 2009;373(9678):1874-1882. https://doi.org/10.1016/S0140-6736(09)60658-9

11. De Beer CR, Van Rooijen AJ, Pretorius, JP, Becker, PJ, Rheeder, P, Paruk, F. Muscle strength and endurance to predict successful extubation in mechanically ventilated patients: A pilot study evaluating the utility of upper limb muscle strength and ergometry. S Afr J Crit Care 2018;34(2): 44-49. DOI:10.7196/SAJCC.2018.v34i2.360

12. Riebe D, Ehrman JK, Liguori G, Magal M, American College of Sports Medicine. ACSM's Guidelines for Exercise Testing and Prescription. 10th ed. Philadelphia: Wolters Kluwer, 2018.

13. Vorona S, Sabatini U, Al-Maqbali S, et al. Inspiratory muscle rehabilitation in critically ill adults. A systematic review and meta-analysis. Ann Am Thorac Soc 2018;15(6):735-744. https://doi. org/10.1513/AnnalsATS.201712-961OC

14. De Jonghe B, Sharshar T, Lefaucheur J-P, et al. Paresis acquired in the intensive care unit: A prospective multicentre study. JAMA 2002;288(22):2859-2867.

15. Elliott D, Denehy L, Berney S, Alison J. Assessing physical function and activity for survivors of a critical illness: A review of instruments. Aust Crit Care 2011;24(3):155-166. https://doi org/10.1016/j.aucc.2011.05.002

16. Vanpee G, Hermans G, Segers J, Gosselink R. Assessment of limb muscle strength in critically ill patients: A systematic review. Crit Care Med 2014;42(3):701-711. https://doi.org/10.1097/ CCM.0000000000000030

17. Denehy L, Skinner EH, Edbrooke L, et al. Exercise rehabilitation for patients with critical illness: A randomised controlled trial with 12 months of follow-up. Crit Care 2013;17(4):R156. https:// doi.org/10.1186/cc12835

18. Poulsen JB, Moller K, Jensen CV, Weisdorf S, Kehlet H, Perner A. Effect of transcutaneous electrical muscle stimulation on muscle volume in patients with septic shock. Crit Care Med 2011;39(3):456-461. https://doi.org/10.1097/CCM.0b013e318205c7bc

19. Routsi C, Gerovasili V, Zervakis D, et al. Electrical muscle stimulation prevents critical illness poly-neuromyopathy in ICU patients - a randomized parallel intervention trial. Intensive Care Medicine Vol 35. Springer 233 Spring St, New York, NY 10013 USA; 2009:133.

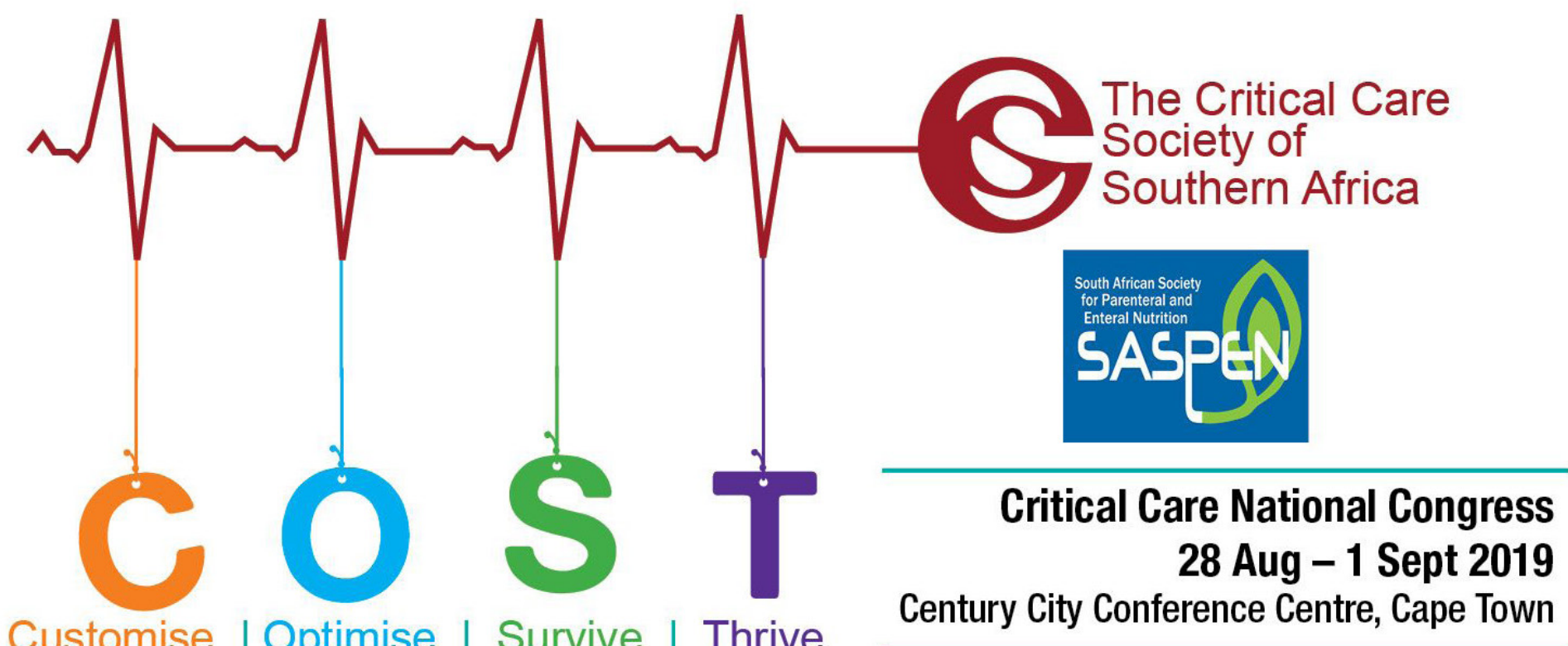

